\title{
Entrenchment and Severance Pay in Optimal Governance Structures
}

\author{
ANDRES ALMAZAN and JAVIER SUAREZ*
}

\begin{abstract}
This paper explores how motivating an incumbent CEO to undertake actions that improve the effectiveness of his management interacts with the firm's policy on CEO replacement. Such policy depends on the presence and the size of severance pay in the CEO's compensation package and on the CEO's influence on the board of directors regarding his own replacement (i.e., entrenchment). We explain when and why the combination of some degree of entrenchment and a sizeable severance package is desirable. The analysis offers predictions about the correlation between entrenchment, severance pay, and incentive compensation.
\end{abstract}

THERE ARE SUBSTANTIAL CROSS-SECTIONAL DIFFERENCES in the control exercised by corporate boards of directors. In some cases, the board can and does fire the CEO at will. In others, directors are effectively the puppets of the CEO and exert independent power only in extreme situations. The standard view in the literature is that, ideally, shareholders should have full control of the board of directors and that any form of CEO entrenchment is necessarily undesirable. This position, however, ignores some important interactions between managerial incentive problems and shareholder activism which we explore here.

Indeed a CEO's influence on the board frequently reflects not so much a discretionary choice of shareholders but the endogenous accumulation of power in the hands of the incumbent CEO (Hermalin and Weisbach, 1998). Yet we challenge the view that full shareholder control of the board of directors is necessarily the most desirable governance structure. We identify a potential conflict between inducing a CEO to improve the effectiveness of his management and allowing the shareholders to benefit from every valuable managerial replacement. We find that the solution to the CEO's incentive problem may rest on the allocation of power in the board of directors as well as on more traditional instruments such as severance pay and incentive compensation. The key insight of our analysis is that, in

*Almazan is from the McCombs School of Business, University of Texas at Austin, and Suarez is from CEMFI, Madrid. We are grateful to Ty Callahan, Murray Carlson, Marco Celentani, Thomas Gehrig, Rick Green, Maria Gutierrez, Gordon Hanka, David Hirshleifer, John Moore, Jorge Padilla, Bob Parrino, Ramesh Rao, Clara Raposo, David Scharfstein, and especially Sheridan Titman and two anonymous referees for their useful comments and suggestions. Any remaining errors are our sole responsibility. 
certain circumstances, shareholders find it convenient to relinquish some power in favor of the CEO in order to save on the overall compensation costs of the firm.

Formally, we model a corporation whose CEO can improve the effectiveness of his management by undertaking some actions. We consider actions that are costly for the CEO, are subject to moral hazard, and have their benefits linked to the CEO's tenure - for instance, the building of a management team, the development of a certain corporate culture, or the establishment of links with other firms based on the CEO's personal contacts. We consider the case in which, after the incumbent CEO invests, a superior rival CEO may become available. We discuss the interaction between CEO compensation and the power that the CEO has, vis-à-vis shareholders, to influence the board of directors over his own replacement.

An optimal corporate governance structure should minimize the cost to shareholders of inducing the incumbent CEO to undertake the relevant actions. Such cost includes the compensation of the CEO as well as the expected value lost by passing up the opportunity to replace the CEO with a superior manager. Under the governance system considered in most of the literature, the CEO is influenced exclusively through a compensation scheme in which severance pay plays a small or no role, and replacement decisions are made by a "strong board" that never passes up a valuable replacement opportunity.

While this structure has obvious merits, it is clearly not what we observe, and, as we show, there are circumstances in which it is not the best for the shareholders. Specifically, in certain circumstances, shareholders can gain by adding severance pay to structures that rely on a "strong" board and, in other circumstances, by shifting to a "weak" board through which the incumbent CEO can effectively veto his own replacement. In both cases, severance pay plays a crucial role, and the overall gain in shareholder value is due to savings on incentive compensation.

With a strong board, severance pay helps solve a time-inconsistency problem related to the possibility of using (untransferable) control rents to compensate the incumbent for his choice of actions. ${ }^{1}$ Shareholders may be interested in committing to a replacement policy that, when a modestly better manager becomes available, replaces the incumbent CEO only if he fails to take the desired actions. Under such a policy, the CEO would realize that taking the right actions makes him more likely to keep enjoying his control rents, and this reduces the required level of incentive pay. To do this, shareholders must provide a level of severance pay that dissuades them from replacing the (diligent) incumbent when a modestly better rival shows up.

\footnotetext{
${ }^{1}$ Several other papers have dealt with time-inconsistency issues in a corporate governance context. Stein (1988) shows that protecting managers from excessive takeover pressure may improve their incentives to undertake long-term investments. Time inconsistency is also a concern in the capital structure choices examined by Titman (1984) and Dewatripont and Tirole (1994), in relation to the firm's liquidation and reorganization policy, and by Berkovitch and Israel (1996), in relation to managerial replacement decisions.
} 
With a weak board in place, severance pay is important for a different reason. In this case, the structure of the board already protects the incumbent CEO and his control rents. Indeed, the replacement of the CEO requires his consent and control rents will tend to make him a tough bargainer in the negotiations that could eventually lead to his replacement. Without further control, a weak board would allow the CEO to entrench and appropriate resources (i.e., control rents or the replacement surplus), even if he does not take the desired actions. However, a sufficiently high level of severance pay may turn things around: A CEO who does not take the desired actions will be unable to credibly threaten to resist being replaced, while one who does take them will be able to do so. Hence, the expected renegotiations with shareholders will end up giving the incumbent CEO a payoff related to the action taken. Such a payoff constitutes a direct reward for the desired actions and allows shareholders to save on incentive compensation, which is less directly related to the relevant actions. ${ }^{2}$

The strong board cum severance pay arrangement works well when control rents are sizable (since they substitute for incentive pay) and the probability of finding a substantially better CEO is not very large (since severance pay increases the cost of these desirable replacements). In contrast, the weak board arrangement is desirable when control rents are low (since control rents increase the resistance of the incumbent to step down and, hence, the cost of severance) and the probability of finding a substantially better CEO is high (since the renegotiations that directly reward the incumbent's actions only take place when such a rival becomes available).

The analysis produces three important implications. First, opposite to the standard negative interpretation given to any measure that increases the protection to an incumbent CEO, in our framework, severance pay and weak boards are substitutes for incentive compensation and their presence should lead to an overall reduction in the cost of managerial compensation. Second, we deliver a simple theory of boards based on the cost of incentive compensation and the size of control rents: We predict that shareholders will prefer to rely on strong boards when incentive compensation is effective or control rents are large, and on weak boards otherwise. Finally, we predict cross-sectional differences in CEOs' optimal compensation packages: Weak boards will feature larger severance pay and lower pay-performance sensitivity than strong boards.

By analyzing the interactions between managerial compensation and entrenchment, our paper connects the existing theoretical literature on boards with the vast literature on managerial incentives and compensation. ${ }^{3} \mathrm{As}$ in Hirshleifer and Thakor (1994), Adams (1998), Hermalin and Weisbach (1998), and Warther (1998), our board is responsible for replacing the CEO. However, instead

\footnotetext{
${ }^{2}$ This finding relates to the point first made by Holmstrom (1979) about the desirability of making incentive compensation contingent on any piece of information correlated with managerial actions. A related insight appears in Scharfstein (1988), who argues that takeovers implicitly make the compensation to the managers of the target depend on the raider's information about the firm.

${ }^{3}$ See Hermalin and Weisbach (2000) for a survey of the literature on boards and Murphy (1999) for a survey of the literature on executive compensation.
} 
of examining the ex post efficiency of replacement decisions taken under imperfect information, we focus on the impact that the anticipated replacement decisions have on the incumbent's ex ante incentives. ${ }^{4}$ Also, instead of examining the endogenous dynamics of director nominations and entrenchment (as in Hermalin and Weisbach, 1998), we focus on the board structure that maximizes ex ante shareholders' value, and, to the best of our knowledge, we are the first in arguing that corporate governance structures that involve some degree of entrenchment can be optimal. ${ }^{5}$

The rest of the paper is organized as follows. Section I describes the model. Sections II and III characterize the optimal CEO compensation and the replacement policies corresponding to a weak board and a strong board, respectively. Section IV compares both types of board and discusses the factors that determine the optimality of one or the other. Section V discusses the implications of our results and their relevance in view of the available evidence. Section VI concludes.

\section{The Model}

We consider a firm that operates in a risk-neutral economy where the market rate of return is normalized to zero. The firm has a project that yields a terminal cash flow $x$, which equals $R$ in case of success and 0 in case of failure. ${ }^{6}$

\section{A. Managers and the Replacement Decision}

Initially, the firm is run by an incumbent CEO who lacks wealth, is protected by limited liability, and has a reservation utility of zero. ${ }^{7}$ The probability of success under his management, denoted by $p$, depends on an action related to a firm-specific human-capital investment that we assume to be necessary for the maximization of shareholders' value. ${ }^{8}$ This investment may represent, for instance, the effort that the incumbent devotes to building an effective management team, the development of a certain corporate culture, or the establishment of linkages with other firms based on the CEO's personal relationships. We assume that, by incurring a private utility cost $B$, the incumbent may increase the probability of success under his management from $p_{L}$ to $p_{H}$.

\footnotetext{
${ }^{4}$ Managerial incentives are also central to the analysis of Berkovitch, Israel, and Spiegel (2000), who examine the impact of capital structure and CEO compensation on the replacement decision, but do not consider the possibility that an entrenched CEO directly influences the decision.

${ }^{5}$ Some degree of entrenchment can also be found in the optimal bankruptcy structures posited by Berkovitch, Israel, and Zender (1997).

${ }^{6}$ The assumption that $x=0$ in case of failure is made without loss of generality. Removing it would simply add innocuous constants to shareholders' expected payoffs.

${ }^{7}$ Under risk neutrality, incentive problems make wealth-constrained managers appropriate rents due to limited liability. These rents imply an incentive-related cost to shareholders if they come out of the firm's cash flow and exceed managers' reservation utilities. We stress the importance of this cost by assuming that reservation utilities are zero.

${ }^{8}$ At the end of Section II, we provide the sufficient condition (8) for this to be the case.
} 
Once the incumbent has decided on his human-capital investment, a better rival manager may become available. ${ }^{9}$ The probability of success under the rival's management is modeled as a random variable $q$ that reflects the rival's personal skills (perhaps due to his prior human-capital investments). With probability $\pi_{0}$, no rival shows up (or, equivalently, $q=0$ ). With probability $\pi_{L}$, a rival shows up with a modest probability of success $q_{L}>p_{H}$. Finally, with probability $\pi_{H}$, a rival shows up with a more substantial probability of success $q_{H}>q_{L}$.

When a rival becomes available, a board of directors must decide whether to substitute the rival for the incumbent $(r=1)$ or not $(r=0)$. Clearly, on expected cash flow grounds, shareholders prefer the rival to the incumbent. However, we assume that the manager who stays in charge up to termination enjoys some nontransferable control rents $C$ that create a conflict between the shareholders and the incumbent on the replacement decision.

Despite this conflict, and regardless of who has the effective control of the replacement decision, the replacement of the incumbent will occur (perhaps after renegotiation) if the expected cash flow gain from the replacement, $(q-p) R$, suffices to compensate the CEO for the loss of $C$. We assume that

$$
p_{L} R+C<q_{L} R<p_{H} R+C<q_{H} R,
$$

so the sole case where the replacement outcome is unclear occurs when the incumbent invests $\left(p=p_{H}\right)$ and the rival is only modestly better than him $\left(q=q_{L}\right)$; in all other cases, the replacement takes place.

\section{B. Information, Contracts, and the Board of Directors}

The investment of the incumbent, $p$, and the quality of the rival, $q$, are observable to both the shareholders and the incumbent at the time of deciding on replacement. Yet we assume that these variables are unverifiable to third parties. Thus, shareholders cannot contract directly on $p$ and $q$, and must use some other means to tackle the incumbent's investment problem (i.e., the inducement of $p_{H}$ ) and the replacement problem (i.e., the determination of the realizations of $q$ for which his replacement occurs). ${ }^{10}$

Specifically, shareholders can condition the compensation of the incumbent CEO on the replacement decision $r$ (severance pay) and the terminal cash flow $x$ (performance pay). In addition, they can determine the extent to which the incumbent may influence the board of directors when it decides on replacement.

For simplicity, we focus on compensation contracts that yield to the incumbent a payment of zero if he is not replaced and the project fails, a bonus $w$ if he is not replaced and the project succeeds, and a constant severance pay $s$ if he is replaced. ${ }^{11}$ Henceforth, the pair $(w, s)$ will denote the incumbent's initial compensation contract.

\footnotetext{
${ }^{9}$ Like the incumbent, the rival also lacks wealth, is protected by limited liability, and has a zero reservation utility.

${ }^{10}$ If such contracting were possible, both problems would interact very little.

${ }^{11}$ As will become apparent below, fixing the compensation when the incumbent is not replaced and the project fails at zero is optimal without loss of generality. In contrast, we lose
} 
When a rival becomes available, the board of directors meets with the incumbent CEO to reach a mutually acceptable agreement on replacement. We model this negotiation by assuming that the incumbent makes a take-it-or-leave-it offer to the representatives of the shareholders. ${ }^{12}$ The offer specifies the decision on replacement, $r$, and the final terms of the incumbent's compensation contract, namely, a bonus $w^{\prime}$ (possibly different form $w$ ) if he is to remain in charge or a severance pay $s^{\prime}$ (possibly different form $s$ ) if he is to step down. In case the offer is rejected, the representatives of the shareholders decide whether, under the terms of the incumbent's initial compensation contract, they find it profitable to replace him or not. If they find it so, the final outcome will depend on how much influence the incumbent has on the board's final decision.

We consider two polar types of board: weak and strong. With the former, the incumbent can effectively oppose (or veto) his replacement; with the latter, he cannot. ${ }^{13}$ We assume that shareholders can choose the firm's type of board either before or simultaneously with offering the incumbent his initial compensation contract. $^{14}$ The sequence of events is summarized in Figure 1.

\section{CEO Compensation with a Weak Board}

This section considers the design of the CEO compensation contract in the case in which the final decision on CEO replacement corresponds to a weak board of directors. Shareholders, anticipating how the initial compensation contract affects the incumbent's investment decision and the negotiations about his replacement, choose a contract that maximizes the expected terminal cash flow of the project net of the costs of CEO compensation (henceforth, shareholder value $)^{15}$

some generality by assuming that the severance pay is constant. It can be shown, however, that a performance-based severance pay would complicate the analysis without qualitatively changing our results.

${ }^{12}$ Our results also hold if the party that takes the initiative and makes a take-it-or-leave-it offer to the other party is a random draw driven by some probabilities $\lambda$ and $1-\lambda$ that represent the exogenous bargaining powers of each party.

${ }^{13}$ We could have generalized our analysis by considering a continuum of board types characterized by the probability $\beta \in[0,1]$ with which the incumbent CEO receives the opportunity to effectively oppose a replacement proposal. As one can infer from the analysis below, however, all the relevant trade-offs would in that case be linear in $\beta$, which makes the solution one of the polar types that we explicitly compare.

${ }^{14}$ In practice, shareholders can regulate the incumbent's influence on the replacement decision through less direct channels than veto power, for instance, by appointing directors who belong to the incumbent management team or whose private interests are connected with the continuation of the incumbent, or by providing the incumbent with means to compensate the directors for their support and loyalty.

${ }^{15}$ The allocation of control over the design of the initial compensation contract to the incumbent would turn out to be suboptimal for shareholders. In the limit, shareholders would be expropriated of the whole net present value of the project. In reality, most corporations prevent this by delegating authority on executive compensation to a committee comprised of independent directors only. 


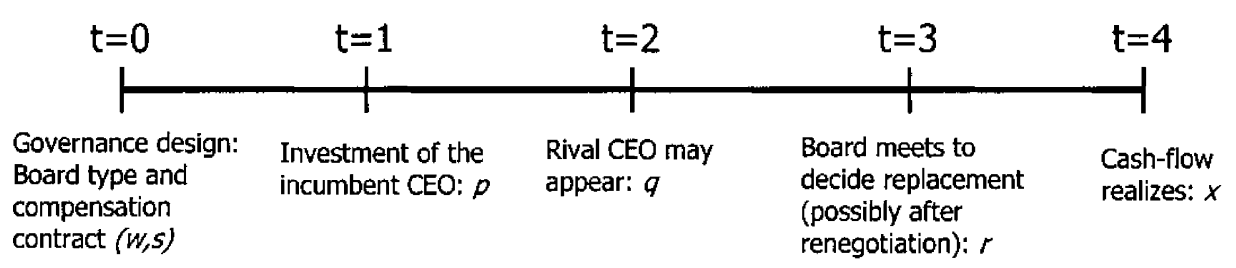

Figure 1. Time line. At $t=0$, shareholders decide whether to establish a weak or a strong board of directors, and set a compensation contract $(w, s)$ for the incumbent CEO. At $t=1$, the incumbent makes his investment decision, $p$. At $t=2$, the uncertainty concerning the availability and quality of a rival, $q$, is resolved. At $t=3$, the board meets to decide on replacement. The outcome is a replacement decision $r$ and, possibly, a new compensation contract $\left(w^{\prime}, s^{\prime}\right)$ for the incumbent. At $t=4$, the cash flow $x$ is realized and the incumbent receives his stipulated compensation.

Before formally characterizing such contract, it is useful to briefly anticipate the main insights of the analysis. A weak board enables the incumbent to preserve his control rents by simply opposing his replacement. Additionally, it may allow the incumbent to threaten the shareholders with such opposition and to force them to concede additional severance pay in exchange for his departure. These considerations suggest that a weak board is vulnerable to entrenchment - the sacrifice of ex post shareholders' value due to the excessive protection of the incumbent CEO. As a result, one may doubt the ex ante optimality of weak boards, as well as the necessity, with them in place, of introducing positive severance pay in the incumbent's initial contract. As it turns out, both conclusions are premature.

Indeed, when a substantially better rival becomes available, a weak board may allow the incumbent to renegotiate his severance pay with shareholders under the threat to oppose, otherwise, his replacement. However, this ex post opportunism can generate ex ante shareholder value by saving on performance-based compensation. It will do so if the incumbent anticipates that his payoff in this renegotiation is larger when he invests than when he does not. Remunerating the incumbent with such a renegotiation payoff, which is directly linked with his investment decision, is cheaper than remunerating him with his bonus, which is only indirectly linked, through performance, with the decision.

But severance pay is key to making the anticipated renegotiation payoff of the incumbent larger if he invests than if he does not. The initially contracted severance pay should be high enough for the incumbent who has not invested to accept stepping down as soon as the board proposes for him to do so. The idea is to make the "carrot" of severance so attractive for the negligent incumbent that he cannot credibly threaten shareholders to oppose his replacement. Thus, he loses all his bargaining power and is unable to extract any rent from his entrenchment.

However, the contracted severance pay should not be too large. Otherwise, even the diligent incumbent, who expects a larger payoff from his bonus, might be willing to step down without resistance. The diligent incumbent should be able to credibly threaten to oppose to his replacement and to extract, through 
renegotiation, part of the surplus brought about with it. Ex ante, the difference between this part of the surplus and the initially contracted severance pay will be seen by the CEO as a direct reward to his diligence, allowing shareholders to save on performance-based compensation. As it is shown in a later section, this savings sometimes makes it optimal to rely on a weak board as a governance structure.

Formally, we proceed in three steps to find the optimal compensation contract. We first look at the stage in which the replacement decision is made and characterize the outcome of the negotiations between the incumbent and the shareholders under an arbitrary initial contract $(w, s)$, each possible choice of $p$, and each realization of $q$. After that, we study how the incumbent's incentives to invest depend on the contract. Finally, we determine which incentive compatible contract is the best.

\section{A. Renegotiation and the Replacement Decision}

Consider the negotiation that occurs in the presence of a given initial compensation contract $(w, s)$ and after the incumbent has made his investment decision $p$ and the uncertainty concerning the rival manager's quality $q$ has been resolved. Let $W$ be the CEO expected pecuniary compensation after $p$ is taken but before $q$ is realized. Of course, when no rival manager is available $(q=0)$, the incumbent stays and his expected pecuniary compensation is $W=p w$, as implied by the terms of the contract. Otherwise, the incumbent and the shareholders negotiate the replacement decision via the board of directors knowing that, in the absence of an agreement, the incumbent cannot be replaced unless he consents.

The negotiation is crucially affected by the (hypothetical) replacement decision that will occur in case of disagreement. In such a case, the incumbent is replaced only if both parties find it convenient under the initial contract. Clearly, shareholders want to replace the incumbent manager if and only if the expected terminal cash flow under the rival, net of the incumbent's severance pay $s$, exceeds the expected terminal cash flow under the incumbent, net of the cost of his bonus $w:^{16}$

$$
q R-s>p(R-w)
$$

The incumbent consents to his replacement if and only if his severance pay exceeds the expected value of the bonus and the control rents that he would obtain if staying:

$$
s>p w+C .
$$

Hence, without an agreement, the replacement will occur if and only if the cash flow gain exceeds the control rent, $(q-p) R>C$, and severance pay is in an intermediate range, $p w+(q-p) R<s<p w+C$.

The negotiations between the incumbent and the shareholders will change the above outcome whenever it is in the interest of both parties. As specified, if

\footnotetext{
${ }^{16}$ If the two net values are equal, we break the tie assuming that the incumbent stays.
} 
such is the case, the incumbent will make a take-it-or-leave-it offer to the shareholders, proposing the alternative replacement decision and some new terms for his compensation contract. The final outcome of the negotiation process is summarized in the following proposition. All proofs of formal results are in the Appendix.

PRoposition 1: With a weak board, the renegotiations about CEO replacement under an initial contract $(w, s)$ yield the following outcome:

1. If $(q-p) R>C$, the incumbent is replaced and his expected pecuniary compensation is

$$
W= \begin{cases}p w+(q-p) R, & \text { if } s \leq p w+C \\ s, & \text { if } s>p w+C\end{cases}
$$

2. If $(q-p) R \leq C$, the incumbent stays and his expected pecuniary compensation is $W=p w$.

Proposition 1 shows that the final replacement decision only depends on whether the cash flow gains from replacing the incumbent exceed or do not exceed his control rent. Specifically, the initially contracted severance pay $s$ does not affect the decision. From (1), the replacement will occur if the incumbent does not invest $\left(p=p_{\mathrm{L}}\right)$ or if, despite investing $\left(p=p_{H}\right)$, the rival is substantially better than him $\left(q=q_{H}\right)$. In positive terms, the incumbent will stay if he invests $\left(p=p_{H}\right)$ and the rival is just modestly better than him $\left(q=q_{L}\right)$.

The initially contracted severance pay $s$ is, however, relevant for the incumbent's expected pecuniary compensation $W$ that emerges from the negotiations at the board. It affects the incumbent's bargaining position vis-à-vis the shareholders. In particular, whenever $s>p w+C$, the incumbent's threat of opposing his replacement is noncredible and, hence, he cannot appropriate more than the contracted severance pay $s$. In contrast, with $s \leq p w+C$, the threat is credible, which allows him to appropriate the surplus from his replacement, $(q-p) R$, by making the proper take-it-or-leave-it offer to shareholders. ${ }^{17}$ As we discuss next, a proper choice of $s$ may allow shareholders to use this surplus as a reward for the incumbent's investment decision.

\section{B. Incentive Compatibility}

To decide whether to invest in improving the quality of his management, the incumbent evaluates whether the corresponding increase in his expected pecuniary and nonpecuniary income exceeds the private cost $B$ of his investment. Accordingly, the incentive compatibility condition for the incumbent to invest can

\footnotetext{
${ }^{17}$ Clearly, with a more even distribution of bargaining power, the surplus would be shared by the incumbent and the shareholders, but the qualitative implications for $W$ would be the same.
} 
be written as

$$
E_{q}\left[W \mid p_{H}\right]-E_{q}\left[W \mid p_{L}\right]+\pi_{L} C \geq B
$$

where the operator $E_{q}[W \mid p]$ implies computing the mathematical expectation of $W$ (given by Proposition 1 ) over the possible realizations of $q$ and conditional on the specified choice of $p$. Notice that investing yields the incumbent additional pecuniary compensation, $E_{q}[W \mid P H]-E_{q}[W \mid P L]$, as well as additional control rents, $\pi_{L} C$, since by investing, he prevents his replacement when the rival's quality is just $q_{L}$.

To see how (4) particularizes in a relevant example, consider the case in which the severance pay $s$ is set just slightly larger than the critical value $p_{L} w+C-$ as it will be in the optimal contract. By Proposition 1, if the incumbent does not invest, his compensation is $W=p_{L} w$ when no rival shows up and $W=s=p_{L} w+C$ otherwise. Instead, if he invests, his compensation is $W=p_{H} w$ when no rival or a modestly better rival shows up and $W=p_{H} w+\left(q_{H}-p_{H}\right) R$ (coming out of a renegotiated severance pay) when a substantially better rival shows up. Consequently, the incentive compatibility condition becomes

$$
\Delta w+\pi_{H}\left[\left(q_{H}-p_{H}\right) R-C\right] \geq B,
$$

where $\Delta \equiv p_{H}-p_{L}$. This inequality identifies a benefit of entrenchment: the possibility of using some entrenchment rents in the provision of incentives. If severance pay is set at the adequate level, the incumbent will realize that investing strengthens his bargaining position in the negotiations prior to his replacement with a substantially better rival. This reduces the bonus $w$ required to guarantee his investment.

\section{The Optimal Initial Contract}

Since the replacement decision with a weak board does not depend on the incumbent's initial compensation contract, any incentive compatible contract will be associated with a value of

$$
V=A R-E_{q}\left[W \mid p_{H}\right]
$$

where $A \equiv \pi_{0} p_{H}+\pi_{L} p_{H}+\pi_{H} q_{H}$. Hence, shareholders will simply choose the incentive compatible contract that minimizes the incumbent's pecuniary compensation.

Our next result describes such an optimal contract under an assumption that avoids the discussion of uninteresting corner solutions (in particular, those in which the optimal bonus $w$ turns out to be zero).

Proposition 2: Suppose that $B>\pi_{H}\left[\left(q_{H}-p_{H}\right) R-C\right]$ and the firm is governed by a weak board of directors. Then a bonus

$$
w_{1}=\frac{B-\pi_{H}\left[\left(q_{H}-p_{H}\right) R-C\right]}{\Delta}
$$

and a severance pay $s_{1}=p_{L} w_{1}+C$ constitute an optimal compensation contract. 
Notice that the proposed optimal contract satisfies the incentive compatibility constraint (5) with equality. Moreover, this is the best contract within the class with $s=p_{L} w+C$, because it minimizes $E_{q}[W \mid P H]$ subject to (5) by minimizing the bonus $w$ and, thereby, the severance pay $s$. To explain why this class of contracts turns out to be optimal, notice that a contract with $s<p_{L} w+C$ would allow the incumbent to abstain from investing and yet, once a substantially better rival shows up, to credibly threaten the shareholders with opposing his replacement. In such a case, renegotiation on replacement will no longer yield rents useful for the provision of incentives and so entrenchment will only have costs for shareholders.

An interesting property of the optimal compensation contract is that the severance pay $s_{1}$ and the bonus $w_{1}$ move together. In particular, the factors that increase $w_{1}$ increase $s_{1}$ as well. From this perspective, severance pay complements (rather than substitutes) performance pay. As we will show, with a strong board, this property will be reversed, opening a channel to empirically test the model.

To conclude this section, we provide a sufficient condition for the incumbent's investment to be optimal for shareholders, as we have assumed so far. Under the characterized optimal contract, the value of the firm equals:

$$
V_{1}=A R-\frac{p_{H}}{\Delta}\left[B-\pi_{H}\left[\left(q_{H}-p_{H}\right) R-C\right]\right]-\pi_{H}\left(q_{H}-p_{H}\right) R .
$$

In contrast, if the incumbent were not to invest, shareholders could just set a bonus $w=0$ and a severance pay $s=p_{L} w+C=C$ (which avoids the incumbent's opportunistic resistance to his replacement after a rival shows up). The resulting value of the firm would be

$$
\bar{V}=\left(\pi_{0} p_{L}+\pi_{L} q_{L}+\pi_{H} q_{H}\right) R-\left(\pi_{L}+\pi_{H}\right) C .
$$

One can immediately check that

$$
\Delta R>\frac{p_{H} B}{\pi_{0} \Delta}
$$

is a sufficient condition for $V_{1}>\bar{V}$, which guarantees the optimality of inducing the incumbent to invest.

\section{CEO Compensation with a Strong Board}

We now consider the case in which the final decision on CEO replacement corresponds to a strong board of directors. As before, we aim to characterize a CEO compensation contract that maximizes shareholder value.

With a strong board, shareholders have full power to replace the CEO, but this does not imply they always want to do so. When the expected cash flow gain suffices to compensate the incumbent CEO for his loss of control rents, efficient renegotiation guarantees that shareholders and the incumbent will agree on the replacement. Otherwise (i.e., when a modestly better rival shows up and the incumbent has invested), efficient renegotiation does not predetermine the replacement decision. Of course, shareholders will ignore the incumbent's control rents ex post, since he lacks the wealth needed to transfer these rents to shareholders. However, from an ex ante perspective, the picture is different. 
Shareholders may want to reward the incumbent for his investment by committing not to replace him if he invests and an only modestly better rival shows up - clearly, if the incumbent does not invest, the replacement occurs since the expected cash flow gain exceeds the value of the incumbent's control rents. Under such a commitment, control rents would serve as a substitute for performance pay, which, as we show, can be a more expensive means of providing incentives to the incumbent.

Shareholders' commitment to such a replacement policy requires an adequate level of severance pay. On the one hand, it must be high enough to solve the underlying time-inconsistency problem; that is, to dissuade shareholders from replacing the incumbent if he invests and a modestly better rival becomes available. On the other hand, it should avoid paying the incumbent unnecessary compensation in those cases where his replacement does take place (including the hypothetical scenarios in which he does not invest). Actually, in some cases, avoiding this unnecessary compensation recommends offering no severance pay at all. Yet, in other cases characterized below, setting a strictly positive level of severance pay is optimal.

As in the formal analysis of the weak board case, we proceed in three steps. We start by looking at the stage in which the negotiations on replacement take place. We characterize the outcome of these negotiations under an arbitrary contract $(w, s)$ and every possible choice of $p$ and realization of $q$. We study later how the contract affects the incumbent's incentives to invest. Finally, we determine which incentive-compatible contract is the best.

\section{A. Negotiation and the Replacement Decision}

Consider the negotiation that occurs in the presence of a given initial compensation contract $(w, s)$ and after the incumbent has made his investment decision $p$ and the uncertainty concerning the rival manager's quality $q$ has been resolved. Of course, if no rival manager is available $(\% q=0)$, the incumbent stays and his expected pecuniary compensation is $W=p w$, as stipulated in the contract. Otherwise, the incumbent and the shareholders will negotiate knowing that, with a strong board, if no agreement is reached, the latter can replace the former at will.

Both parties anticipate the (hypothetical) replacement decision in case of disagreement. The replacement of the incumbent simply requires that shareholders find it profitable under the initial contract. For this to be the case, the expected terminal cash flow under the incumbent, net of the cost of his bonus $w$, should be lower than the terminal expected cash flow under the rival, net of the incumbent's severance pay $s:^{18}$

$$
p(R-w)<q R-s
$$

\footnotetext{
${ }^{18}$ As before, if the two net values are equal, we break the tie assuming that the incumbent stays.
} 
Thus, with a sufficiently large severance pay, $s \geq p w+(q-p) R$, shareholders prefer that the incumbent stays.

The hypothetical replacement decision fixes the threat point of the incumbent and the shareholders when negotiating about replacement. Importantly, the incumbent's compensation contract and the replacement decision may be changed by mutual agreement. Proposition 3 summarizes the outcome of the various possible renegotiations.

PRoposition 3: With a strong board, the renegotiations about CEO replacement under an initial contract $(w, s)$ yield the following outcome:

1. If $(q-p) R>C$, the incumbent is replaced and his pecuniary compensation is $W=\min \{p w+(q-p) R, s\}$.

2. If $(q-p) R \leq C$ and $s<(q-p) R$, the incumbent is replaced and his pecuniary compensation is $W=s$.

3. If $(q-p) R \leq C$ and $s \geq(q-p) R$, the incumbent stays and his pecuniary compensation is $W=\min \{p w, s-(q-p) R\}$.

Recalling (1), Proposition 3 confirms that, with a strong board, the only case where efficient renegotiation does not predetermine the replacement decision occurs when the incumbent invests $\left(p=p_{H}\right)$ and the rival is only modestly better than him $\left(q=q_{L}\right)$. Different from the weak board case, the final replacement decision in this case depends on the initially contracted severance pay $s$. In particular, shareholders prefer that the incumbent stays if and only if $s \geq\left(q_{L}-p_{H}\right) R$, since compensating him for his severance in this case would cost more than the whole cash flow gain from his replacement.

Thus, $s=\left(q_{L}-p_{H}\right) R$ is the minimum severance pay with which shareholders can commit not to replace the incumbent when $p=p_{H}$ and $q=q_{L}$. Precisely at this point, the incumbent's expected pecuniary compensation $W$ presents a discontinuity. A lower $s$ would associate with a discretely larger $W$. This discontinuity reflects that pecuniary compensation and control rents are substitutes: In the renegotiation, the incumbent will, in the limit, accept a zero continuation bonus $\left(w^{\prime}=0\right)$ in order to stay and keep his control rent $C$. This substitutability may allow shareholders to save on pecuniary compensation and will be crucial to the design of the optimal initial contract.

\section{B. Incentive Compatibility}

To decide on his investment, the incumbent compares the private cost of making it, $B$, with the increase that the larger probability of success produces in his expected pecuniary and nonpecuniary income. Compactly written, his incentive compatibility condition reads

$$
E_{q}\left[W+(1-r) C \mid p_{H}\right]-E_{q}\left[W+(1-r) C \mid p_{L}\right] \geq B
$$


where the expected pecuniary compensation, $W$, and the values of the variable representing the replacement decision, $r$, for every possible combination of $p$ and $q$ can be obtained from Proposition 3.

As suggested by Proposition 3, we consider a partition of the set of initial contracts according to whether they do or do not prevent the replacement of the incumbent when he invests $\left(p=p_{H}\right)$ and an only modestly better rival is available $\left(q=q_{L}\right)$. The following result particularizes the incentive compatibility condition to the two resulting sets of contracts.

Proposition 4: With a strong board, if severance pay does not protect the incumbent who invests from being replaced with a modestly better rival (i.e., $s<\left(q_{L}-p_{H}\right) R$ ) then the incentive compatibility condition holds if and only if

$$
\pi_{0} \Delta w \geq B
$$

Otherwise, a necessary condition for incentive compatibility is

$$
\pi_{0} \Delta w+\pi_{L}\left[C-\left(q_{L}-p_{H}\right) R\right] \geq B,
$$

which is also sufficient if $s=\left(q_{L}-p_{H}\right) R$.

The main implication of this result is that, introducing a strictly positive level of severance pay, in particular $s=\left(q_{L}-p_{H}\right) R$, reduces the size of the bonus $w$ required to induce the incumbent to invest. As reflected in (11) and (12), the potential savings on $w$ is proportional to the term $\pi_{L}\left[C-\left(q_{L}-p_{H}\right) R\right]$, which measures the net surplus (control rents included) from retaining the incumbent when a modestly better rival becomes available. The incumbent perceives this surplus (that he would not receive without investing) as a reward for his investment.

As we confirm below, setting severance pay in excess of $s=\left(q_{L}-p_{H}\right) R$ is never optimal. In addition to making equilibrium replacements more costly to shareholders, it would worsen the incumbent's incentives: It would further encourage him not to invest and to simply wait for the generous (initial or renegotiated) severance pay that he would receive if replaced.

\section{The Optimal Initial Contract}

To identify the incentive-compatible initial compensation contract $(w, s)$ that maximizes shareholder value, we will compare the cheapest incentive-compatible contracts in each of the two sets mentioned above. The values relevant for the comparison are

$$
V_{2}=A R-\frac{p_{H}}{\Delta} B+\pi_{L}\left(q_{L}-p_{H}\right) R
$$

for the set with $s<\left(q_{L}-p_{H}\right) R$, and

$$
V_{3}=A R-\frac{p_{H}}{\Delta}\left[B-\pi_{L}\left[C-\left(q_{L}-p_{H}\right) R\right]\right]-\pi_{H}\left(q_{L}-p_{H}\right) R,
$$

for the set with $s \geq\left(q_{L}-p_{H}\right) R$. The formal result is the following proposition. 
Proposition 5: Suppose that the firm is governed by a strong board of directors. If $V_{2} \geq V_{3}$, then a bonus

$$
w_{2}=\frac{B}{\pi_{0} \Delta}
$$

and a severance pay $s_{2}=0$ constitute an optimal compensation contract. Otherwise, $a$ bonus

$$
w_{3}=\frac{B-\pi_{L}\left[C-\left(q_{L}-p_{H}\right) R\right]}{\pi_{0} \Delta}
$$

and a severance pay $s_{3}=\left(q_{L}-p_{H}\right) R$ constitute an optimal compensation contract.

By direct application of Proposition 3, the contract without severance pay, $\left(w_{2}, s_{2}\right)$, implies that the incumbent is replaced whenever a rival becomes available, while the contract with severance pay, $\left(w_{3}, s_{3}\right)$, implies that the replacement occurs only if the rival is substantially better. Clearly, we have $w_{3}<w_{2}$, so the presence of severance pay (i.e., the compensation coming from the control rents preserved through it) substitutes for performance-based compensation. Moreover, the savings related to the smaller bonus make the second term in the expression for $V_{3}$ smaller than its counterpart in $V_{2}$.

However, under a strong board, the contract with severance pay features two shortcomings. First, it precludes the expected cash flow gain that a modestly better rival might bring about, which is reflected in the third term in (13). Second, it imposes a direct cost on the replacement of the incumbent with a substantially better rival, hence the third term in (14).

Whether severance pay is or is not part of the optimal compensation contract depends on the comparison of $V_{2}$ and $V_{3}$. But we relegate further discussion of this issue to the next section, where we examine the alternative corporate governance structures as a whole and elaborate on the empirical implications of our results.

To conclude the section, we check that condition (8) is sufficient to guarantee the optimality of inducing the incumbent to invest (i.e., to choose $p_{H}$ ). Notice that to implement $p_{L}$, shareholders could optimally set $w=s=0$ and, accordingly, replace the incumbent CEO whenever a rival shows up. The resulting shareholder value would be

$$
\overline{\bar{V}}=\left(\pi_{0} p_{L}+\pi_{L} q_{L}+\pi_{H} q_{H}\right) R,
$$

which is lower than $\max \left\{V_{2}, V_{3}\right\}$.

\section{The Optimal Governance Structure}

Our analysis of the optimal compensation contracts under both weak and strong boards has identified three potentially optimal corporate governance structures: $G_{1}$, with a weak board and a CEO compensation contract $\left(w_{1}, s_{1}\right)$ based on low performance pay and high severance pay; $G_{2}$, with a strong board 
and a compensation contract $\left(w_{2}, s_{2}\right)$ based on high performance pay and no severance pay; and $G_{3}$, also with a strong board and a compensation contract $\left(w_{3}\right.$, $s_{3}$ ) based on moderate performance pay and moderate severance pay. ${ }^{19}$ In this section, we study the factors that lead each of these candidate structures to emerge as the optimal one. ${ }^{20}$

We can use the expressions for shareholder value in (7), (13), and (14) to characterize the set of parameter values where each structure dominates. We focus on the regions that emerge when varying two relevant parameters. The first is the probability of success under the incumbent CEO if he does not invest, $p_{L}$, which is a measure of the difficulty of solving his incentive problem using performancebased rewards. Intuitively, as $p_{L}$ approaches $p_{H}$, performance becomes a less precise signal of the incumbent's investment decision, so, other things equal, a larger bonus must be offered to guarantee that he invests. ${ }^{21}$ The second relevant parameter is the value of the control rents, $C$, that the incumbent loses if replaced, which measures the importance of the entrenchment problem in weak boards and the time-inconsistency problem in strong boards. Notice these problems are two sides of the same coin: either too much or too little preoccupation about the incumbent's untransferable benefits from remaining in charge.

In Figure 2, we represent the indifference conditions $V_{1}=V_{2}, V_{2}=V_{3}$, and $V_{3}=V_{1}$ over the rectangle where $p_{L} \in\left[0, p_{H}\right]$ and $C \in\left[\left(q_{L}-p_{H}\right) R,\left(q_{H}-p_{H}\right) R\right]$. These conditions define straight lines that divide the rectangle into three polygons in each of which one of our candidate governance structures is optimal. $^{22}$

The structure $G_{1}$ (weak board) is optimal in the region where performance is a rather noisy signal of the CEO's investment (i.e., $p_{L}$ is high) and control rents are small. High noise makes performance-based compensation highly costly. The structure $G_{1}$ saves on this compensation by partly rewarding the incumbent with power to bargain on his dismissal. Yet, in order to guarantee that the incumbent cannot credibly threaten to oppose his replacement if he abstains from investing, shareholders need to offer him severance pay. With small control rents, the required level of severance pay is small, but otherwise entrenchment may be too costly to avoid. ${ }^{23}$

\footnotetext{
${ }^{19}$ This description arises from the comparison of the contracts characterized in Propositions 2 and 5 . We compare $\mathrm{w}_{1}$ and $w_{3}$ at the indifference frontier, where $V_{1}=V_{3}$. It is immediate to check that $V_{1} \geq V_{3}$ implies $w_{1}<w_{3}$.

${ }^{20}$ For a quick check that any of them can turn out to be optimal, suppose $R=100, B=5$, $p_{L}=0.5, p_{H}=0.75, q_{L}=0.81, q_{H}=0.99$, and $\pi_{L}=\pi_{H}=1 / 6$. The only parameter that remains to be fixed is $C$. Elementary computations for values of $C$ equal to 9,15 , and 21 show that $G_{1}, G_{2}$, and $G_{3}$ are, respectively, the structure that maximizes shareholder value. Notice that the proposed parameter configurations satisfy (1), (8), and the assumption included in Proposition 2.

${ }^{21}$ Notice that, for a given $p_{H}$, an increase in $p_{L}$ reduces $\Delta$, which clearly is a key determinant of the size of the bonus $w$ in the three candidate structures.

${ }^{22}$ Further details about the derivation of Figure 2 can be found in the proof of Proposition 7 .

${ }^{23}$ Note that the level of severance pay required to avoid entrenchment if the incumbent does not invest, $s_{1}$, increases one-by-one with $C$.
} 


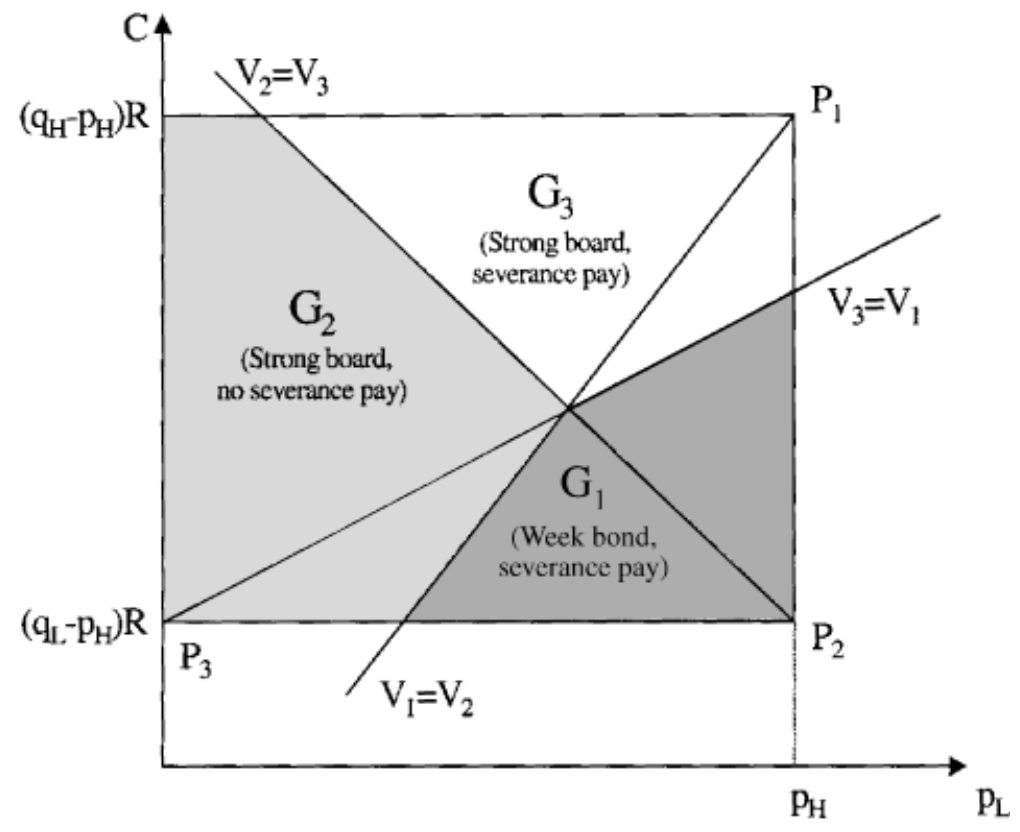

Figure 2. Optimal structures. This figure depicts the various regions of the parameter space (as described by the parameters $p_{L}$ and $C$ ) in which each of the candidate governance structures (G1, G2, and G3) is optimal. The boundaries of these regions are defined by shareholders' indifference conditions $V_{1}=V_{2}, V_{2}=V_{3}$, and $V_{3}=V_{1}$.

When control rents make entrenchment a too severe problem, $G_{3}$ (strong board, severance pay) becomes optimal. Because performance is still a noisy signal of the incumbent's investment, shareholders remain interested in alternatives to performance-based compensation. The solution is to partly reward the incumbent's investment by not replacing him when a modestly better rival becomes available. In this way, the big control rents are used in the favor of shareholders. Interestingly, severance pay is also needed in this structure, but in a very different role: It allows shareholders to credibly commit to such a "soft" replacement policy.

Finally, the corporate governance structure commonly perceived as the ideal one, $G_{2}$ (strong board, no severance pay), is optimal when performance is a sufficiently good signal of the incumbent's investment (i.e., $p_{L}$ is low), and control rents are neither low enough to recommend $G_{1}$ nor high enough to recommend $G_{3}$.

A consequence of the very different functions played by severance pay in $G_{1}$ and $G_{3}$ is that performance-based compensation and severance pay complement each other (i.e., they move in the same direction in response to parameter changes) in weak boards, while they may substitute for each other (i.e., they sometimes move in opposite directions in response to those changes) in strong boards. The following proposition states this result formally for the case in which the varying parameter is $C$. 
PRoposition 6: Consider a sample of firms that differ in C. Then, performance-based compensation (i.e., $w$ ) and severance pay (i.e., s) will be negatively correlated across firms with a strong board, while they will be positively correlated across firms with a weak board.

Both $G_{1}$ and $G_{3}$ use the CEO replacement policy as a partial substitute for performance-based compensation. However, while $G_{1}$ rewards the incumbent's investment through the renegotiation that precedes his replacement when a significantly better rival becomes available, $G_{3}$ rewards it by allowing the incumbent to preserve his control rents when a modestly better rival shows up. Thus, the choice between $G_{1}$ and $G_{3}$ will be driven by how likely rivals are to be either significantly or just modestly better. In fact, we have the following proposition.

Proposition 7: In a sample of firms that differ in $p_{L}$ and $C$, an improvement in the quality of the rivals (i.e., a rise in $\pi_{H} / \pi_{L}$ ) will increase the incidence of $G_{1}$ and decrease the incidence of $G_{1}$.

According to this proposition, we would predict a larger incidence of strong boards in industries or periods of time where the prospects of major technical or organizational innovation increase the quality of the managerial improvements that can only be implemented by replacing the incumbent CEOs. ${ }^{24}$

\section{Discussion of the Results}

In this section, we discuss our results from two different angles. First, we comment on their relevance and plausibility in light of the existing literature and some anecdotal evidence on boards, CEO replacements, and CEO compensation. Second, we discuss their implications for the uses and optimal level of severance pay, relative to the evidence on the role of severance agreements in some American corporations.

\section{A. Can Weak Boards Create Shareholder Value?}

While there seems to be a consensus on the advantages of strong boards, ${ }^{25}$ the business press has recently reported on the "excessive" pressure that some corporations are exerting on their CEOs, on the reduction of the length of CEOs' tenures, and on CEO replacements that do not follow any obvious mistake or any sign of poor performance. ${ }^{26}$ These reports raise questions of whether the

\footnotetext{
${ }^{24}$ Such a move towards strong boards would be compatible with an average increase in managerial turnover. Clearly, in strong boards, if $\pi_{H}$ increases, turnover increases. Moreover, increasing $\pi_{H}$ relative to $\pi_{L}$ expands the $G_{1}$ region and contracts the $G_{3}$ region. However, the effect on the $G_{2}$ region is ambiguous. But, if the increase in $\pi_{H}$ relative to $\pi_{L}$ does not reduce $\pi_{L}+\pi_{H}$ and does not significantly decrease the number of firms using $G_{2}$, then the increase in $\pi_{H}$ will indeed lead to greater turnover.

${ }^{25}$ For instance, Jensen (1993) argues that boards exert insufficient discipline on managers.

${ }^{26}$ In the front page of its December 11, 2000, issue, Business Week refers to it as "The CEO Trap." Bianco and Lavelle write: "They're dropping like flies-from Coke's Doug Ivester to
} 
CEO was adequately protected to make the right decisions in the firm and of whether, to accomplish that, it could have been more desirable for shareholders to have yielded to the CEO a stronger influence on the board. ${ }^{27}$

In our model, firm-specific factors determine the optimal degree of CEO influence on the board. Consistent with the consensus view, strong boards are optimal when control rents make the risk of entrenchment too large or when performance pay is not too costly. However, shareholders may want to give more power to the CEO when control rents are low and when motivating the CEO through performance pay is very costly. ${ }^{28}$

Hermalin and Weisbach (1988) report that CEOs with longer tenures are more likely to nominate insiders as directors, which is consistent with the hypothesis that CEOs get more powerful over time. ${ }^{29}$ However, if the present value of control rents is large for young or recently designated CEOs and declines as CEOs approach their retirement ages, the observed pattern is also consistent with our prediction that weak boards will tend to associate with low control rents.

An alternative strategy to test the validity of our predictions would be to analyze the changes in governance structures induced by the changes in the cost effectiveness of incentive pay. ${ }^{30}$ In terms of Figure 2, a fall in $p_{L}$ should imply, across firms with strong boards, either savings on performance pay without further changes in the governance structure (i.e., while remaining in $G_{2}$ or $G_{3}$ ) or a move towards greater performance sensitivity, lower severance pay, and greater turnover (i.e., a shift from $G_{3}$ to $G_{2}$ ). In contrast, across firms with a weak board, such a change should allow either reductions in the levels of both performance pay and severance pay without further changes in the governance structure (i.e., while remaining in $G_{1}$ ) or a shift towards a stronger board and, thus, greater performance sensitivity, lower severance pay, and greater turnover (i.e., a move from $G_{1}$ to $\left.G_{2}\right)$.

It should be emphasized that the governance structures that we have characterized maximize ex ante shareholders' value. However, in reality, structures

Lucent's Rich McGinn. Some are victims of technological change, others of poor execution.” In the same article, Warren Buffet was quoted about the replacement of Michael Hawley from Gillette: "We felt we had a very good person in Hawley, but we made a decision [that] it was possible to find a better one.

${ }^{27}$ In some cases, this may be necessary in order to attract the CEO to the job. An article by Steve Hamm (1999) in Business Week reports on the difficulties of Compaq Computer Corporation to attract a top-flight executive given the reputation of aggressiveness of its board.

${ }^{28}$ And they sometimes do! In Business Week, Jennifer Reingold (2000) writes that among firms in the internet sector, a "new board model" is emerging: Small boards that are "packed with insiders" have become the standard practice. This might not be independent from Meulbroek's (2000) evidence on the large costs of incentive compensation for firms in the internet sector.

${ }^{29}$ Hermalin and Weisbach (1998) interpret this fact as consistent with their prediction that CEOs endogenously accumulate power over their tenure.

${ }^{30}$ Murphy (1999) documents that the increased use of performance pay advocated by Jensen and Murphy (1990) did actually take place during the 1990s, perhaps encouraged by regulations such as the SEC's New Compensation Disclosure Rules and the limits to the tax deductibility of any non-performance-related pay in excess of one million dollars. 
designed according to the preferences of an already entrenched CEO will hardly feature the combination of board strength and CEO compensation that our analysis predicts. Thus, when the conflict between managers and shareholders extends to the very design of the firm's governance structure, the value of our analysis becomes primarily normative (rather than positive). Admittedly, a clear-cut empirical distinction between optimal and suboptimal governance structures could be hard to obtain. ${ }^{31}$ Yet, our result that the "desirable" forms of entrenchment are substitutes for incentive compensation suggests a potential channel for such a distinction: Other things equal, a "desirable" move towards a weak board should provoke observable savings on managerial compensation, while an "undesirable" move is very likely to produce the opposite.

The distinction between desirable and undesirable entrenchment seems necessary to interpret some of the reported empirical linkages between managerial compensation and boards. For instance, Core, Holthausen, and Larcker (1999) report that CEOs earn greater total compensation when governance structures are less effective, which seems to support the view that entrenchment is undesirable. However, they also find that increasing the percentage of inside directors in the board reduces all measures of CEO compensation, as well as the ratio of variable to total compensation. So perhaps some dimensions of entrenchment are, as we predict, desirable. ${ }^{32}$

\section{B. The Roles of Severance Pay}

Our analysis stresses the influence of severance pay on the CEO replacement choice. In general, both in weak and strong boards, it serves to moderate the temptations of the party with residual control rights on the replacement decision to behave opportunistically against the other. In strong boards, it protects the CEO from the shareholders' tendency to replace him too frequently. ${ }^{33}$ In weak boards, it protects shareholders from the CEO's tendency to resist excessively his own replacement. ${ }^{34}$ In both cases, severance pay allows shareholders to limit the use of costly performance-based managerial compensation.

Proxy statements provide anecdotal evidence consistent with both types of protective roles. For instance, the 1984 proxy statement of Saint Regis Paper states that severance payments "could be among the considerations which might

\footnotetext{
${ }^{31}$ See Hermalin and Weisbach (2000) for a discussion of the difficulties of interpreting the evidence about boards.

${ }^{32}$ Less clear is the correlation between pay-performance sensitivity and board size, the other main proxy used by the empirical literature to measure board effectiveness. Yermack (1996) finds that pay-performance sensitivity decreases with board size, but Core et al. (1999) find the opposite.

${ }^{33}$ Knoeber (1986) and Berkovitch and Khanna (1991) attribute a similar role to golden parachutes in hostile tender offers: They argue that shareholders may want to renege on implicit long-term compensation already earned but not yet received by the manager.

${ }^{34}$ To the best of our knowledge, this role has been so far ignored by the academic literature. In the context of mergers, Harris (1990) refers to the potential effect of golden parachutes in negotiations between management and bidders, suggesting that, due to their potential salary losses, managers without golden parachutes may reject bids that increase shareholder value.
} 
discourage certain takeover attempts due to costs attributable to the departure of senior officers. The reason why this protection may be desirable appears in the 1995 proxy statement (p. 10) of Apple Computer: "to reinforce and encourage the continued attention and dedication of members of Apple's management in the atmosphere of uncertainty that might arise in the context of a change in control and that could result in the departure or distraction of management personnel to the detriment of the Company and its shareholders." At the other side of the spectrum, the 1985 proxy statement (p. 8) of Hughes Tool captures the idea of preventing inconvenient resistance to change. Specifically, it refers to how the golden parachutes given to their managers should allow them to evaluate proposals of corporate control changes "without being influenced by the uncertainty of their own situations."

The evidence on the use of golden parachutes in the context of corporate acquisitions may give an idea of parachutes' role and importance. ${ }^{35}$ On the one hand, Agrawal and Knoeber (1998) document how the protection given by golden parachutes reduces the need to compensate managers subject to takeovers threats. On the other hand, Lefanowicz, Robinson, and Smith (2000), using a sample of 306 acquisitions completed between 1980 and 1995, find that golden parachutes were present in 59 percent of the target firms and that their use and scope expanded dramatically over the studied period. In their data, and consistent with the role attributed to severance pay in our weak boards, golden parachutes seem to facilitate CEO turnover: Acquiring firms did not employ the incumbent CEO in 67 percent of the firms with golden parachutes contracts, as opposed to 51 percent of the firms without them. However, the correlation between golden parachute use and board composition shows that firms with independent boards use golden parachutes in 68 percent of the cases, while the rest of the firms use them in only 48 percent of the cases. If this second group identifies firms with weak boards, then our analysis would imply that an important number of them are stuck in suboptimal governance structures - since severance pay should always accompany such board. ${ }^{36}$

An additional perspective on the empirical plausibility of the proposed roles of severance pay can be gathered by comparing its magnitude with that of other variables suggested in the analysis. ${ }^{37}$ In this respect, Lefanowicz et al. (2000) estimate that severance payments to managers of acquired firms represents on average 2.2 percent of the pre-announcement market value of their equity, which gives an indication of the size of the improvements that severance pay might have

\footnotetext{
${ }^{35}$ According to Section $280 \mathrm{G}$ of the Internal Revenue Code, a golden parachute is an agreement that a firm adopts with its CEO or manager group for a severance payment that is contingent on a change in the ownership or effective control of the corporation, or in the ownership of a substantial portion of its assets. However, quite commonly, severance payments of the same amount are to be made "in the event the corporation terminates his employment, other than for cause or mandatory retirement" (taken from the 1995 proxy statement of Phelps Dodge, p. 20).

${ }^{36}$ Cochran, Wood, and Jones (1985) also report that firms with a high proportion of inside directors are less likely to grant golden parachute contracts to managers.

${ }^{37}$ We thank an anonymous referee for suggesting these comparisons.
} 
blocked if replacement decisions had corresponded to a strong board. ${ }^{38}$ On the other hand, they report that severance agreements commonly amount to five times the yearly compensation of the displaced manager, which, under a weak board, would have meant preventing entrenchment for control rents worth up to four times the manager's yearly compensation. ${ }^{39}$ Of course, these numbers do not substitute for a formal statistical test of our predictions, but encourage us to call for further research in this area.

\section{Concluding Remarks}

We have explored how the problem of motivating a CEO to invest in improving the effectiveness of his management interacts with the firm's policy on CEO replacement. From a shareholders' perspective, the firms' corporate governance structure should be designed to minimize the sum of two types of costs: the cost of CEO compensation and the value lost if passing up good replacement opportunities. Proposals in favor of a strong board through which shareholders can fire the $\mathrm{CEO}$ without restraint do well in the replacement dimension, but may need to be accompanied by very onerous incentive compensation. The reason is that the CEO may find himself replaced after having taken costly actions to improve the firm, but before performance-based rewards properly compensate him for them.

We have examined solutions based on incentive compensation, severance pay, and the possibility of yielding the CEO some influence on the board of directors regarding his own replacement. We have identified two relevant alternatives to the pure strong board arrangement. One is a modification consistent in including positive severance pay and using the thereby protected control rents of the CEO as a part of the compensation for his investment. The other implies a more radical move toward a weak board, through which the CEO can threaten to resist his replacement and extract rents from shareholders in the subsequent renegotiations. We have shown how the entrenchment risk involved in this arrangement can be prevented using severance pay and how, in such a case, the renegotiations on replacement constitute an effective way to reward the CEO for his investments.

\section{Appendix}

Proof of Proposition 1: To examine the various renegotiation possibilities, let $d$ denote the hypothetical replacement decision that would emerge in the absence of an agreement. Suppose first that either (2) or (3) fail, so $d=0$. The renegotiation will then consist of finding an alternative severance pay $s^{\prime} \geq 0$ (higher

\footnotetext{
${ }^{38}$ Recall that in our strong board arrangement severance pay equals the value of the marginal managerial improvement (see Proposition 5).

${ }^{39} \mathrm{In}$ our weak board arrangement, severance pay increases one-by-one with the value of the CEO's control rents (see Proposition 2). Many severance agreements grant just three years of compensation since the Deficit Reduction Act of 1984 fixed the maximum deductible severance payment in that amount. Later on, the Budget Reconciliation Act of 1992 disallowed the deductibility of any compensation not related to performance (including severance pay) in excess of one million dollars.
} 
than $s$ ) such that both the incumbent and the shareholders gain by setting $r=1$ and enforcing $s^{\prime}$. Given the status-quo payoffs, a proposal $s^{\prime}$ is acceptable to shareholders if it verifies $q R-s^{\prime} \geq p(R-w)$, while it is acceptable to the CEO if it verifies $s^{\prime} \geq p w+C$. The compatibility of these two inequalities requires

$$
(q-p) R \geq C
$$

in which case renegotiation leads to $r=1$ and a take-it-or-leave-offer $s^{\prime}=$ $p w+(q-p) R$ from the CEO to the shareholders such that his pecuniary compensation ends up being $W=p w+(q-p) R$. In contrast, if condition (A1) fails, we have $r=d=0$, and $W=p w$, as stipulated in the initial contract.

Suppose next that conditions (2) and (3) hold, so $d=1$. In this case, the renegotiation will consist in specifying an alternative salary $w^{\prime} \geq 0$ (higher than $w$ ) for the incumbent such that both parties end up (weakly) better off setting $r=0$ and enforcing $w^{\prime}$ rather than $w$. Given the status-quo payoffs associated with $d=1$ under the initial contract, shareholders will accept $w^{\prime}$ if $p\left(R-w^{\prime}\right) \geq q R-s$, while the incumbent will accept it if $p w^{\prime}+C \geq s$. So having a mutually beneficial renegotiation requires $(q-p) R \leq C$, which is impossible given (2) and (3). Therefore, we have $r=d=1$ and $W=s$, as stipulated in the initial contract. Reordering the relevant conditions, we get the results stated in the proposition.

Proof of Proposition 2: Proposition 1 suggests considering contracts within three classes: (a) $s \leq p_{L} w+C$, (b) $p_{L} w+C<s \leq p_{H} w+C$, and (c) $s>p_{H} w+C$. Consider first contracts of class (b). The value of the firm is

$$
V=A R-p_{H} w-\pi_{H}\left(q_{H}-p_{H}\right) R,
$$

which is decreasing in $w$ and independent of $s$, while the incentive compatibility constraint (4) requires

$$
\pi_{0} \Delta w+\pi_{L}\left(p_{H} w-s\right)+\pi_{H}\left(p_{H} w-s\right)+\pi_{H}\left(q_{H}-p_{H}\right) R \geq B-\pi_{L} C,
$$

which imposes a lower bound on $w$. Since reducing $s$ loosens the bound on $w$ but is innocuous for (A2), the best contract within this class implies a severance pay at the minimum admissible value $s=p_{L} w+C$. Under this choice, the lowest value of $w$ that satisfies (A3) is

$$
w_{1}=\frac{B-\pi_{H}\left[\left(q_{H}-p_{H}\right) R-C\right]}{\Delta},
$$

which leads to

$$
V_{1}=A R-\frac{p_{H}}{\Delta}\left[B-\pi_{H}\left[\left(q_{H}-p_{H}\right) R-C\right]\right]-\pi_{H}\left(q_{H}-p_{H}\right) R .
$$

Notice that the nonnegativity of $w_{1}$ is guaranteed by the assumption $B>\pi_{H}\left[\left(q_{H}-p_{H}\right) R-C\right]$.

Consider next contracts of class (a). Shareholders' payoff has the same expression as in (A2), decreasing in $w$ and independent of $s$. However, the incentive compatibility condition is now

$$
\Delta w-\pi_{L}\left(q_{L}-p_{L}\right) R-\pi_{H} \Delta R \geq B-\pi_{L} C,
$$


which imposes a lower bound on $w$ clearly larger than $w_{1}$. Hence, any contract of class (a) will be strictly dominated by the already identified best contract of class (b).

Consider finally contracts of class (c). The value of the firm is

$$
V=A R-\pi_{0} p_{H} w-\pi_{L} p_{H} w-\pi_{H} s,
$$

which is decreasing in both $w$ and $s$, while the incentive compatibility constraint requires

$$
\pi_{0} \Delta w+\pi_{L}\left(p_{H} w-s\right) \geq B-\pi_{L} C,
$$

which imposes a lower bound on $w$. Since reducing $s$ loosens the bound on $w$ and increases (A4), the best contract within this class implies a severance pay at the minimum admissible value $s=p_{H} w+C$. Under this choice, the lowest value of $w$ that satisfies (A4) is

$$
\hat{w}=\frac{B}{\pi_{0} \Delta}
$$

which leads to

$$
\hat{V}=A R-p_{H} \frac{B}{\pi_{0} \Delta}-\pi_{H} C .
$$

One can easily check, however, that $\pi_{0}<1$ and $\left(q_{H}-p_{H}\right) R>C$ imply $V_{1}>\hat{V}$. Hence, the best contract of class (c) is also dominated by the already identified best contract of class (b), which, consequently, is the optimal contract.

Proof of Proposition 3: Suppose first that (9) holds, so $d=0$. In this case, the renegotiation will consist of finding an alternative severance pay $s^{\prime} \geq 0$ (lower than $s$ ) such that both parties end up (weakly) better off setting $r=1$ and enforcing $s^{\prime}$ rather that $s$. Given the status-quo payoffs associated with $d=0$ under the initial contract, the proposal $s^{\prime}$ will be acceptable to the shareholders if it verifies $q R-s^{\prime} \geq p(R-w)$, while it will be acceptable to the CEO if it verifies $s^{\prime} \geq p w+C$. The compatibility of these two inequalities requires that there exists $s^{\prime}$ such that

$$
p w+(q-p) R \geq s^{\prime} \geq p w+C
$$

Thus, if

$$
(q-p) R \geq C
$$

the renegotiation will lead to $r=1$. In particular, according to the assumed renegotiation procedure, the incumbent CEO will make a take-it-or-leave-offer $s^{\prime}=p w+(q-p) R$ to the shareholders, leaving them at their status-quo level of utility. The pecuniary compensation of the CEO will then be

$$
W=p w+(q-p) R .
$$


In contrast, if condition (A6) fails, the final replacement decision will be $r=d=0$, and the expected pecuniary compensation of the CEO will be

$$
W=p w
$$

as stipulated in the initial contract.

Suppose next that condition (9) does not hold, so $d=1$. In this case, the renegotiation will consist in specifying an alternative salary $w^{\prime} \geq 0$ (lower than $w$ ) for the incumbent CEO such that both parties end up (weakly) better off setting $r=0$ and enforcing $w^{\prime}$ rather than $w$. Given the status-quo payoffs associated with $d=1$ under the initial contract, a mutually acceptable $w^{\prime}$ should satisfy $p\left(R-w^{\prime}\right) \geq q R-s$ on the shareholders' side, and $p w^{\prime}+C \geq s$ on the CEO side. These two inequalities imply

$$
(q-p) R \leq s-p w^{\prime} \leq C .
$$

Hence, a mutually beneficial renegotiation requires both

$$
(q-p) R \leq C
$$

and, by the nonnegativity of $w^{\prime}$,

$$
s \geq(q-p) R .
$$

Thus, if conditions (A7) and (A8) are satisfied, the renegotiation will lead to $r=0$. In particular, according to the assumed renegotiation procedure, the incumbent CEO will make a take-it-or-leave-offer $p w^{\prime}=s-(q-p) R$ to the shareholders, leaving them at their status-quo level of utility. The expected pecuniary compensation of the CEO will then be

$$
W=s-(q-p) R .
$$

In contrast, if either (A7) or (A8) fail, the final replacement decision will be $r=d=1$, and the pecuniary compensation of the CEO will be $W=s$, as stipulated in the initial contract. After some reordering of the relevant conditions, we get the results stated in the proposition.

Proof of Proposition 4: Using Proposition 3 (together with prior observations about the case $q=0$ ), we can obtain an explicit expression for the manager's expected income when he does not invest:

$$
\begin{aligned}
E_{q}\left[W+(1-r) C \mid p_{L}\right]= & \pi_{0}\left(p_{L} w+C\right)+\pi_{L} \min \left\{p_{L} w+\left(q_{L}-p_{L}\right) R, s\right\} \\
& +\pi_{H} \min \left\{p_{L} w+\left(q_{H}-p_{L}\right) R, s\right\} .
\end{aligned}
$$

This expression reflects that the incumbent keeps his job only in case no rival manager becomes available. When a rival manager appears, the incumbent receives either the initially contracted severance pay $s$, if it is not too high, or, otherwise, a new one fixed through renegotiation.

For the case in which the manager invests, our discussion following Proposition 3 suggests considering two separate cases. Suppose first that $s<\left(q_{L}-p_{H}\right) R$. 
Then

$$
E_{q}\left[W+(1-r) C \mid p_{H}\right]=\pi_{0}\left(p_{H} w+C\right)+\pi_{L} s+\pi_{H} \min \left\{p_{H} w+\left(q_{H}-p_{H}\right) R, s\right\},
$$

where the last two terms are obtained from Proposition 3, noting that $\left(q_{L}-p_{H}\right) R<C$ and $\left(q_{H}-p_{H}\right) R>C$, respectively. Moreover, since $p_{H} w+\left(q_{H}-\right.$ $\left.p_{H}\right) R>\left(q_{L}-p_{H}\right) R>s$, the last term simplifies to $\pi_{H}$. So we have

$$
E_{q}\left[W+(1-r) C \mid p_{H}\right]=\pi_{0}\left(p_{H} w+C\right)+\pi_{L} s+\pi_{H} s .
$$

For similar reasons, the last two terms in (A9) also simplify to $\pi_{L} s$ and $\pi_{H} s$ respectively. Thus, the incentive compatibility condition (10) reduces to:

$$
\pi_{0} \Delta w \geq B
$$

Suppose next that $s \geq\left(q_{L}-p_{H}\right) R$. Then if $p=p_{H}$, the incumbent will keep his job both when $q=0$ and when $q=q_{\mathrm{L}}$, so we have

$$
\begin{gathered}
E_{q}\left[W+(1-r) C \mid p_{H}\right]=\pi_{0}\left(p_{H} w+C\right)+\pi_{L}\left[\min \left\{p_{H} w, s-\left(q_{L}-p_{H}\right) R\right\}+C\right] \\
+\pi_{H} \min \left\{p_{H} w+\left(q_{H}-p_{H}\right) R, s\right\}
\end{gathered},
$$

which, in order to facilitate the comparison with (A9), can be reordered as follows:

$$
\begin{aligned}
E_{q}\left[W+(1-r) C \mid p_{H}\right] & =\pi_{0}\left(p_{H} w+C\right)+\pi_{L} \min \left\{p_{H} w+\left(q_{L}-p_{H}\right) R, s\right\} \\
+ & \pi_{H} \min \left\{p_{H} w+\left(q_{H}-p_{H}\right) R, s\right\}+\pi_{L}\left[C-\left(q_{L}-p_{H}\right) R\right] .
\end{aligned}
$$

Interestingly, the severance pay $s$ only affects the second and third terms in (A9) and (A10). Comparing them makes clear that

$$
\pi_{j} \min \left\{p_{L} w+\left(q_{j}-p_{L}\right) R, s\right\} \geq \pi_{j} \min \left\{p_{H} w+\left(q_{j}-p_{H}\right) R, s\right\},
$$

for all $s \geq\left(q_{L}-p_{H}\right) R, w \leq R$, and $j=L, H$. Moreover, within the specified ranges for $s$ and $w$, this relationship holds with equality for $j=L, H$ only if $s=\left(q_{L}-p_{H}\right) R$. For this value of $s$, the incentive compatibility condition (10) reduces to

$$
\pi_{0} \Delta w+\pi_{L}\left[C-\left(q_{L}-p_{H}\right) R\right] \geq B,
$$

whereas for values of $s$ above $\left(q_{L}-p_{H}\right) R$, some extra negative terms will appear in the left-hand side, tightening the corresponding constraint on $w$.

Proof of Proposition 5: Suppose first that the optimal contract specifies $s<\left(q_{L}-p_{H}\right) R$ so that $r=1$ at $\left(p_{H}, q_{L}\right)$. Then the decisions (and possible renegotiations) on replacement imply

$$
V=\pi_{0} p_{H}(R-w)+\pi_{L}\left(q_{L} R-s\right)+\pi_{H}\left(q_{H} R-s\right),
$$

whereas incentive compatibility requires that (11) is satisfied. Clearly, since $V$ is decreasing in $w$ and $s$, the optimal contract should set $(w, s)=\left(w_{2}, 0\right)$, where

$$
w_{2}=\frac{B}{\pi_{0} \Delta}
$$


is the bonus that satisfies (11) with equality. Under this contract, shareholders will obtain

$$
V_{2}=A R-\frac{p_{H}}{\Delta} B+\pi_{L}\left(q_{L}-p_{H}\right) R
$$

where $A=\left(\pi_{0}+\pi_{L}\right) p_{H}+\pi_{H} q_{H}$.

Suppose next that the optimal contract specifies $s \geq\left(q_{L}-p_{H}\right) R$ so that $r=0$ at $\left(p_{H}, q_{L}\right)$. In this case, the decisions (and possible renegotiations) on replacement imply

$$
\begin{aligned}
V & =\pi_{0} p_{H}(R-w)+\pi_{L}\left[p_{H} R-\min \left\{p_{H} w, s-\left(q_{L}-p_{H}\right) R\right\}\right] \\
& +\pi_{H}\left[q_{H} R-\min \left\{p_{H} w+\left(q_{H}-p_{H}\right) R, s\right\}\right] .
\end{aligned}
$$

This expression is also decreasing in $w$ and $s$. Moreover, we have already discussed that setting $s>\left(q_{L}-p_{H}\right) R$ would tighten the corresponding incentive compatibility constraint. Hence, it is optimal to set $(w, s)=\left(w_{3}, \mathrm{~s}_{3}\right)$, where

$$
w_{3}=\frac{B-\pi_{L}\left[C-\left(q_{L}-p_{H}\right) R\right]}{\pi_{0} \Delta}
$$

is the bonus that satisfies (12) with equality, whereas

$$
s_{3}=\left(q_{L}-p_{H}\right) R
$$

is the minimum severance pay that dissuades shareholders from replacing the incumbent manager at $\left(p_{H}, q_{L}\right)$. Under this contract, shareholders will get

$$
V_{3}=A R-\frac{p_{H}}{\Delta}\left[B-\pi_{L}\left[C-\left(q_{L}-p_{H}\right) R\right]\right]-\pi_{H}\left(q_{L}-p_{H}\right) R .
$$

The comparison of $V_{2}$ and $V_{3}$ determines which contract is the best.

Proof of Proposition 6: Consider first the firms with a strong board. According to Figure 2, if $C$ is low, they will use $G_{2}$, that is, $w=w_{2}>w_{3}$ and $s=0<s_{3}$, where $w_{2}$ is invariant to $C$. As $C$ increases, firms will switch to $G_{3}$, where $w_{3}$ is decreasing in $C$, while $s_{3}$ is invariant to $C$ (see Proposition 5). Consider next the firms with a dependent board. In this case, all of them use $w=w_{1}$, which is increasing in $C$, and $s=s_{1}$, which is also increasing in $C$ (see Proposition 2).

Proof of Proposition 7: The argument is based on Figure 2. Condition $V_{1}=V_{2}$ is equivalent to

$$
\left[\pi_{L}\left(p_{H}-p_{L}\right)\left(q_{L}-p_{H}\right)-\pi_{H} p_{L}\left(q_{H}-p_{H}\right)\right] R+\pi_{H} p_{H} C=0
$$

and defines an upward-sloping straight line that goes through the point $\left(p_{L}, C\right)=\left(p_{H},\left(q_{H}-p_{H}\right) R\right)$, which is denoted by $P_{1}$. Points below this line have $V_{1}>V_{2}$. Similarly, condition $V_{2}=V_{3}$ is equivalent to

$$
\left[\left(\pi_{L}+\pi_{H}\right)\left(p_{H}-p_{L}\right)+\pi_{L} p_{H}\right]\left(q_{L}-p_{H}\right) R-\pi_{L} p_{H} C=0,
$$

and defines a downward-sloping line that passes through the point $\left(p_{L}, C\right)=\left(p_{H},\left(q_{L}-p_{H}\right) R\right)$, which is denoted by $P_{2}$. Points below this line imply 
$V_{2}>V_{3}$. Finally, the condition $V_{3}=V_{1}$ is equivalent to

$$
\left[\left(\pi_{L}+\pi_{H}\right) p_{H}\left(q_{L}-p_{H}\right)+\pi_{H} p_{L}\left(q_{H}-q_{L}\right)\right] R-\left(\pi_{L}+\pi_{H}\right) p_{H} C=0
$$

and defines an upward-sloping line (with slope smaller than that of the $V_{1}=V_{2}$ line) that passes through the point $\left(p_{L}, C\right)=\left(0,\left(q_{L}-p_{H}\right) R\right)$, which is denoted by $P_{3}$. Points below this line imply $V_{3}<V_{1}$. The three lines intersect at a single point and end up dividing the parameter space in the three regions depicted in Figure 2. To prove the results stated in the proposition, notice that changes in $\pi_{H}$ and $\pi_{L}$ do not move $P_{1}, P_{2}$, and $P_{3}$, but produce rotations in the relevant lines around these points. In particular, increasing $\pi_{H}$ relative to $\pi_{L}$ decreases the slope of the $V_{1}=V_{2}$ line, increases the absolute value of the slope of the $V_{2}=V_{3}$ line, and increases the slope of the $V_{3}=V_{1}$ line. The implied changes expand the region where $G_{1}$ dominates and contract the region where $G_{3}$ dominates, which proves the result.

\section{REFERENCES}

Adams, Renée B., 1998, The dual role of corporate boards as advisors and monitors of management, mimeograph, University of Chicago.

Agrawal, Anup, and Charles Knoeber, 1998, Managerial compensation and the threat of takeover, Journal of Financial Economics 47, 219-339.

Apple Computer, 1995 Proxy statement, SEC web site http://web.lexis-nexis.com/universe.

Berkovitch, Elazar, and Ronen Israel, 1996, The design of internal control and capital structure, Review of Financial Studies 9, 209-240.

Berkovitch, Elazar, Ronen Israel, and Yossef Spiegel, 2000, Managerial compensation and capital structure, Journal of Economics and Management Strategy 9, 549-584.

Berkovitch, Elazar, Ronen Israel, and Jaime F. Zender, 1997, Optimal bankruptcy law and firm-specific investments, European Economic Review 41, 487-497.

Berkovitch, Elazar, and Naveen Khanna, 1991, A theory of acquisition markets: Mergers versus tender offers, and golden parachutes, Review of Financial Studies 4, 149-174.

Bianco, Anthony, and Louis Lavelle, 2000, The CEO trap, Business Week, December 11, web site http: www.businessweek.com.

Cochran, P. L., R. A. Wood, and T. B. Jones, 1985, The composition of boards of directors and incidence of golden parachutes, Academy of Management Journal 28, 664-671.

Core, John E., Robert W. Holthausen, and David F. Larcker, 1999, Corporate governance, chief executive officer compensation, and firm performance, Journal of Financial Economics 51, 371-406.

Dewatripont, Mathias, and Jean Tirole, 1994, A theory of debt and equity: Diversity of securities and manager-shareholder congruence, Quarterly Journal of Economics 109, 1027-1054.

Hamm, Steven, 1999, A board too strong for its own good? Chairman Rosen and his team run the show-making the CEO search more difficult, Business Week, July 12, web site http: www.businessweek.com.

Harris, Ellie, 1990, Antitakeover measures, golden parachutes, and target firm shareholder value, Rand Journal of Economics 21, 614-625.

Hermalin, Benjamin E., and Michael S. Weisbach, 1988, The determinants of board composition, Rand Journal of Economics 19, 589-606.

Hermalin, Benjamin E., and Michael S. Weisbach, 1998, Endogenously chosen boards of directors and their monitoring of the CEO, American Economic Review 88, 96-118.

Hermalin, Benjamin E., and Michael S. Weisbach, 2000, Board of directors as an endogenously determined institution: A survey of the economic literature, mimeograph, University of Illinois.

Hirshleifer, David A., and Anjan V. Thakor, 1994, Managerial performance, boards of directors, and takeover bidding, Journal of Corporate Finance 1, 63-90. 
Holmstrom, Bengt, 1979, Moral hazard and observability, Bell Journal of Economics 10, 74-91.

Hughes Tool, 1985 Proxy statement, SEC web site http://web.lexis-nexis.com/universe.

Internal Revenue Code, U.S. Department of Treasury, web site http://uscode.house.gov/usc.htm.

Jensen, Michael C., 1993, The modern industrial revolution, exit, and the failure of internal control systems, Journal of Finance 48, 831-880.

Jensen, Michael C., and Kevin J. Murphy, 1990, Performance pay and top-management incentives, Journal of Political Economy 98, 225-264.

Knoeber, Charles, 1986, Golden parachutes, shark repellents, and hostile tender offers, American Economic Review 76, 155-167.

Lefanowicz, Craig E., John R. Robinson, and Reed Smith, 2000, Golden parachutes and managerial incentives in corporate acquisitions: Evidence from the 1980s and 1990s, Journal of Corporate Finance 6, 215-239.

Meulbroek, Lisa K., 2000, The efficiency of equity-linked compensation: Understanding the full cost of awarding executive stock options, Working paper 00-056, Harvard Business School.

Murphy, Kevin J., 1999, Executive compensation, in OrleyAshenfelter and David Card, Eds.: Handbook of Labor Economics, Volume 3 (North-Holland, New York).

Phelps Dodge, 1995 Proxy statement, SEC web site http://web.lexis-nexis.com/universe.

Reingold, Jennifer, 2000, Dot.com boards are flouting the rules: They're small and packed with insiders. Does it matter? Business Week, January 17, web site http: www.businessweek.com.

Scharfstein, David, 1988, The disciplinary role of takeovers, Review of Economic Studies 55, 185-199.

Stein, Jeremy C., 1988, Takeover threats and managerial myopia, Journal of Political Economy 96, 61-80.

Titman, Sheridan, 1984, The effect of capital structure on a firm's liquidation decision, Journal of Financial Economics 13, 137-151.

Warther,Vincent A., 1998, Board effectiveness and board dissent: A model of the board's relationship to management and shareholders, Journal of Corporate Finance 4, 53-70.

Yermack, David, 1996, Higher market valuation of companies with a small board of directors, Journal of Financial Economics 40, 185-211. 
